\title{
Veterans Administration
}

\section{Automatic transmission for electric wheelchairs*}

\author{
JAMES B. RESWICK, SC.D. \\ Director, Rehabilitation Research and Development Evaluation Unit, \\ Veterans Administration, Washington, $D C$
}

\begin{abstract}
A new infinitely variable automatic transmission called the RESATRAN' that automatically changes its speed ratio in response to load torque being transmitted is presented. A prototype has been built and tested on a conventional three-wheeled electric motor propelled wheelchair. It is shown theoretically that more than 50 percent reduction in power during hill climbing may be expected when a transmission-equipped wheelchair is compared to a direct-drive vehicle operating at the same voltage. It is suggested that with such a transmission, wheelchairs can use much smaller motors and associated electronic controls, while at the same time gaining in efficiency that results in longer operating distances for the same battery charge. Design details of the transmission and test results are presented. These results show a substantial reduction in operating current and increased distance of operation over a test course.
\end{abstract}

\section{INTRODUCTION}

This paper presents a description of a new, infinitely variable automatic transmission suitable for use on electric wheelchairs (as well as other vehicles). It also presents test results of the performance of a standard three-wheeled wheelchair equipped with a prototype transmission as compared with the performance of the wheelchair without the transmission.

\footnotetext{
* This paper originates from a personally funded study performed during the author's own personal spare time and is in no way connected with this agency.

Address reprint requests to Dr. Reswick's home address: 1003 Dead Run Dr., McLean, VA 22101.
}

+ Pat. Pend.

\section{BACKGROUND}

\section{The Problem}

Permanent magnet direct current electric motors are widely used in electric wheelchairs because the magnets produce a very strong field with no $\mathrm{I}^{2} \mathrm{R}$ loss. In such motors, torque is directly proportional to armature current. Back electromotive force (emf; the voltage generated by the motor) is directly proportional to motor speed with the maximum speed of a motor determined by the speed at which its back emf just equals the applied voltage. As a result, both torque and current are inversely proportional to motor speed. Motor efficiency is directly proportional to motor speed up to about 80 percent of its operating range, reaches a limit at higher speeds and falls off to zero at maximum speed. As a result of these characteristics, most electric wheelchairs operate inefficiently much of the time.

Many electric wheelchairs use some form of direct drive involving belts, chains and/or gears. On a smooth level surface, relatively little torque is required to propel the wheelchair and occupant at constant speeds of up to 5 or $6 \mathrm{mph}$. If this were the only requirement, small motors of a few hundred watts capacity would serve. But wheelchairs must overeome obstacles, usually at low speed, climb substantial grades and accelerate at a reasonable rate. All of these conditions demand high torque and most often at low speed. Thus, 
most powered wheelchairs are equipped with motors (and associated electronic controls) that are much larger than necessary for level constant speed propulsion and which are required to operate with poor efficiency much of the time since high torque is obtained only at low speed.

\section{Theoretical Solution}

A variable speed ratio transmission that automatically increases its speed ratio as a function of transmitted torque used between the motor and the wheels would do much to solve both of the above-mentioned problems. It would provide increased torque to the wheels when needed at low speeds while at the same time allowing the motor to run faster in a more efficient range. It would permit substantially smaller motors (and associated wiring and controls) to be used without degrading performance unduly and would increase the range of wheelchairs between battery charges when they operate with many stops and starts and climb grades.

\section{Theoretical Example Showing Expected Improvement}

Consider an electric wheelchair equipped with a torque responsive variable speed transmission. Assume "ideal" motor characteristics and a 100 percent efficient transmission. The operating characteristics will depend on the well-known DC PM motor characteristics and the transmission parameters. Let us further assume that the transmission changes its speed ratio from 1 to 3 as torque increases. The initial torque at which a change starts and the stiffness of a spring (which determines when the maximum ratio is reached) are the two parameters that govern operating characteristics of the system. Let us assume the following relationships on which to base calculations:

$$
\text { Speed ratio, } \begin{aligned}
r= & 1 \text { for } 0<\mathrm{T}_{M} /\left(\mathrm{T}_{\mathrm{M}}\right)_{\max }<0.2 \\
\mathrm{r}= & 10 \mathrm{~T}_{M} /\left(\mathrm{T}_{\mathrm{M}}\right)_{\max }-1 \text { for } \\
& 0.2<\mathrm{T}_{\mathrm{M}} /\left(\mathrm{T}_{\mathrm{M}}\right)_{\max }<0.4 \\
\mathrm{r}= & 3 \text { for } 0.4<\mathrm{T}_{\mathrm{M}} /\left(\mathrm{T}_{\mathrm{M}}\right)_{\max }<1
\end{aligned}
$$

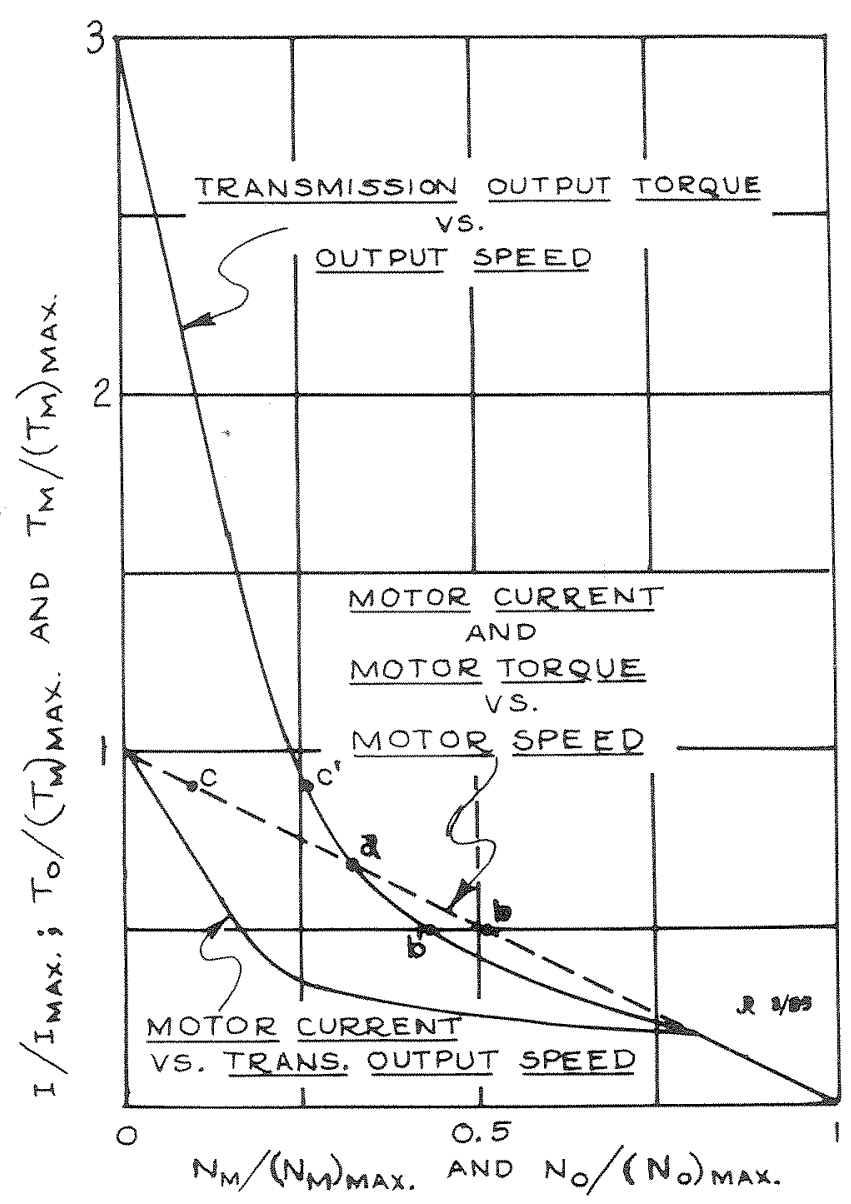

FIGURE

Theoretical torque and current characteristies versus output speed. Both motor (direct-drive output) and variable speed transmission output speeds are on abscissa. All variables are nondimensional and relate to maximum values except for output torque, which relates to maximum motor torque. Applied voltage is constant in all cases.

where $r=$ speed ratio of transmission, (output speed $=1 / \mathrm{r} \times$ motor speed $) ; \mathrm{T}_{M}=$ motor torque; and $\left(\mathrm{T}_{\mathrm{M}}\right)_{\max }=$ maximum motor torque. The range chosen above was shown from separate computer studies to be a reasonable design objective.

With the use of the preceding equations and standard DC PM motor relations, overall system characteristics were calculated (Fig. 1). All variables are nondimensional. Operation of the wheelchair without the transmission is equivalent to the motor characteristics shown by the dotted line when the abscissa is interpreted as a nondimensional ratio of wheelchair speed/maximum wheelchair speed. 

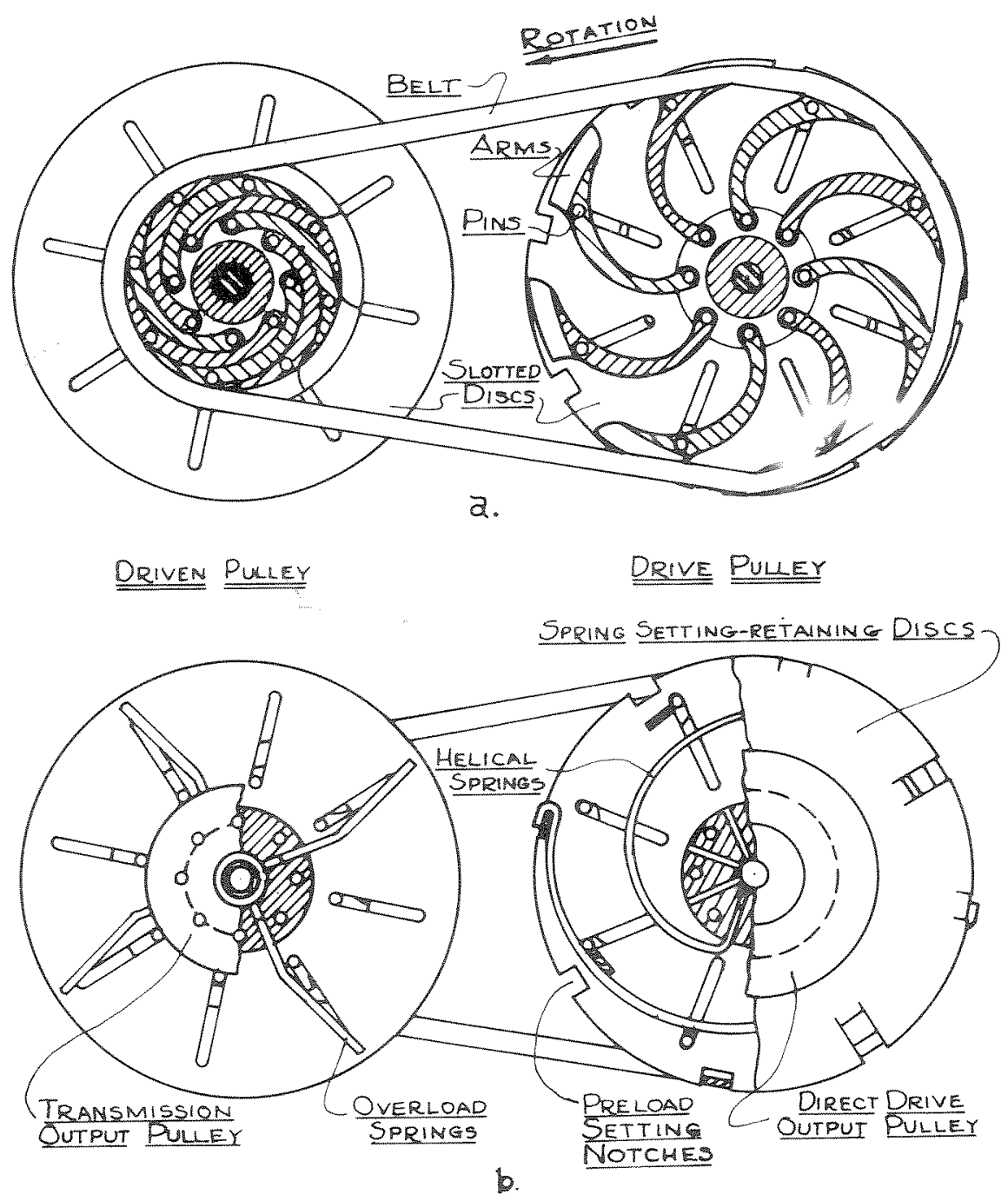

FIGURE 2

RESATRAN automatic variable speed transmission. A: section; $B$ : side view.

Comparative observations can be made by referring to Figure 1. Consider operation of the wheelchair on a hill that requires the torque shown at point $a$. It will be climbing at a speed of about 0.3 of its theoretical maximum and since point $a$ lies on both curves, this speed will be the same with or without the transmission. The required current with the transmission will, however, be more than 50 percent less at the same applied voltage. Thus power is 50 percent less and efficiency is increased by 100 percent.

Consider point $b$ which represents operation of the direct-driven wheelchair on a lesser slope that requires 0.5 of maximum motor torque. Speed is now 0.5 of maximum. Ope tion at the same torque for the transmission-equipped wheelchair is shown at point $b^{\prime}$. Again the current is nearly 50 percent less, but the speed has dropped about 17 percent.

Now consider point $c$ which represents a very high torque and current requirement for the direct-driven wheelchair which might be encountered when starting up against a curb or bump or climbing a very steep ramp. Operation with the transmission is shown at $c^{\prime}$. In this case the current is nearly 60 percent less and, if climbing, the speed would actually increase by over 100 percent.

These points were chosen to represent relatively scere demands. When the wheelchair is 
RESWICK: RESATRAN automatic transmission

operated on the level surface at higher speeds, the difference between the two systems disappears; in this case, above 0.8 of maximum, no difference would be expected.

In summary, it has been shown theoretically that major savings in power required for operating a wheelchair under high-load conditions can be achieved without significant loss of performance at higher speeds through the use of a torque-responsive variable speed transmission. The following sections of this paper describe how the author built and tested such a system.

\section{REQUIREMENTS AND PRESENTLY AVAILABLE SOLUTIONS}

A variable-speed transmission for wheelchair use requires a speed ratio variation of about $3: 1$. It must be relatively small and lightweight, simple in design and reliable and cost to the wheelchair manufacturer should approximate the savings gained from smaller motors and lower power electronics. It should be quiet and durable with minimum and easy maintenance. Its mechanical efficiency must be high (above 95 percent) if overall efficiency gains are to be realized. These are difficult requirements to meet and may be the reason why no such system is in present use.

These are some conventional solutions: A system of multiple gears with automatic shifting between sets of discrete ratios would have good mechanical efficiency, but would require a possibly complex control and shifting system. Its potential size and cost are not attractive. $\mathrm{Hy}-$ draulic transmissions suffer mainly from poor mechanical efficiency, usually not exceeding 85 percent, and they often require costly components. Probably the most attractive candidate is the well-known Reeves drive that uses pairs of cones and a relatively wide and thick $\mathrm{V}$-belt. The cones may be spring loaded to allow the belt to spread the cones apart as torque increases and reduce its effective diameter. The major disadvantage of the Reeves drive is its relatively poor mechanical efficiency compared with standard Vbelt drive; this poor efficiency is caused by the necessarily larger belt surface contact area and associated slipping.

\section{DESIGN OF PROTOTYPE TRANSMISSION}

The author designed a novel automatic variable speed ratio transmission, the RESATRAN', as a prototype intended for use on a commercially available electric wheelchair for test and comparative evaluation. Figures $2 A$ and $2 B$ show the details of construction; Figure 3 shows actual parts laid out during assembly; and Figure 4 shows the completed transmission. The RESATRAN consists of two equal-size V-belt driven pulleys. The "drive" pulley is located on the motor shaft, and the "driven" pulley rotates freely on a fixed shaft. The pulleys are constructed of almost identical parts, but each functions in a different way. Each pulley has a hub, eight freely articulating arms attached to the hub, and two radially slotted dises that are free to rotate on the hubs. The arms have heads that in crosssection form V-grooves for the belt and are shaped so that when nested in their minimum diameter position, form essentially a solid V-grooved pulley. These arms are provided with pins that ride in the radial slots of the disks. These are the common elements in the pulleys; the differences are described next.

The drive pulley has two outer disks designed to retain four helical springs (two on each side), to couple the springs to the slotted disks and to easily set a chosen preload on the springs. One end of each spring is inserted into the hub and the other end catches around a tab on the outer disk that fits into a slot on the inner disk.

The driven pulley has no helical springs but instead has eight radial bars that serve as very stiff cantilever springs. These bars come into play only when the driven pulley arms are near their outermost position at which time elongated pins that extend beyond the disc slots come into contact. The radial bars have no effect during most of the operation of the driven pulley; they serve only to transmit torque under the maximum load condition as when climbing a steep hill.

When assembled (Fig. 4), the preload of the helical springs in the drive pulley tends to extend the arms equally to their outermost position. The center distance between the pulleys is adjusted so that the outer edges of the arms are tangent $t$ the disks and a substantial belt tension is ps 


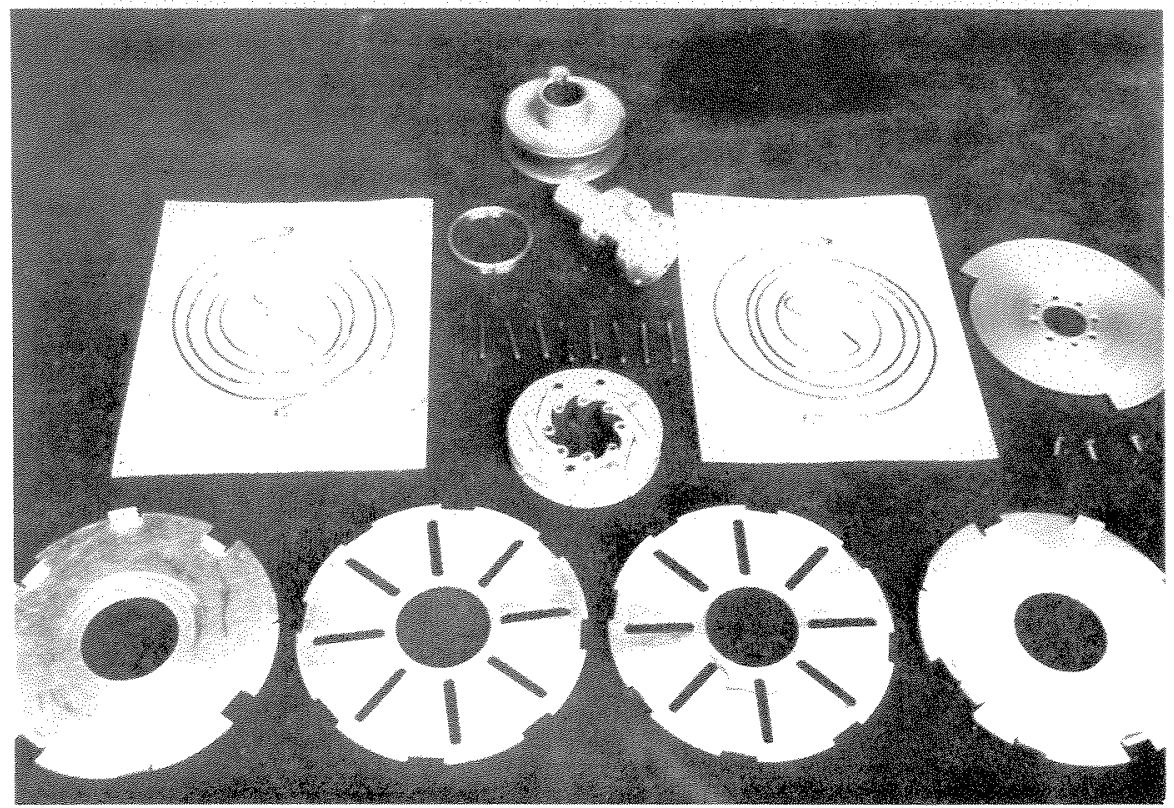

FIGURE 3

Parts of drive pulley. duced. The driven pulley assumes a minimum radius with arms nested, as shown in Figure $2 A$.

\section{OPERATION OF RESATRAN}

In operation, the drive remains in its initial configuration up to the point where the transmitted torque overcomes the preload torque of the springs. This is intended to cover the range of wheelchair operation on smooth level surfaces where torque requirements are low and higher speeds are desired. As load demand increases and torque rises, the arm-disk assembly of the driver rotates with respect to the hub and reduces its effective diameter. The driven pulley arms are pulled outward by the belt tension. This action is surprisingly fast and reliable, comprising a stable self-regulating system: When the torque reaches a high value determined by the spring constant, the drive-pulley arms become nested and the driven pulley arms, being fully extended, apply torque directly to the radial bars, thus relieving the arms of any further increase in force to transmit through their curved beams to the hub. The motor may increase its torque output up to its limit, while the transmission speed ratio remains constant at its maximum value. As torque demand falls off, the sequence of events is reversed. The initial ratio is $0.56: 1$ and the final ratio is $1.77: 1$ with an overall change hy a factor of 3.17. Thus the output torque is mutiplied by a factor of nearly 3.2 at high loads.

\section{WHEELCHAIR TESTS}

\section{The Test Vehicle}

For the test program, which the author conducted in his personal spare time, a threewheeled vehicle called the CycleChair ${ }^{\mathrm{TM}}$ (Electric Mobility Corporation; Sewell, NJ) was obtained. This vehicle was selected because it drives from a single motor through a differential gear. It uses 20 -inch wheels and is designed for indoor-outdoor use. The drive train employs a $1 / 2$ inch belt from the motor to a backshaft and a chain to the differential. This arrangement made it easy to adapt the RESATRAN to the vehicle. As shown in Figure 4, the assembly was mounted on an aluminum plate that is symmetrically slotted so that two mounting positions are possible-one with the drive belt on the motor pulley (normal operation) and the other with the drive belt on the pulley of the RESATRAN driven pulley (automatic drive operation). This arrangement permitted easy change from normal to RESATRAN driven operation and vice versa for comparative testing. An electronic bicycle speedometer/odometer that measured rpm directly was also 


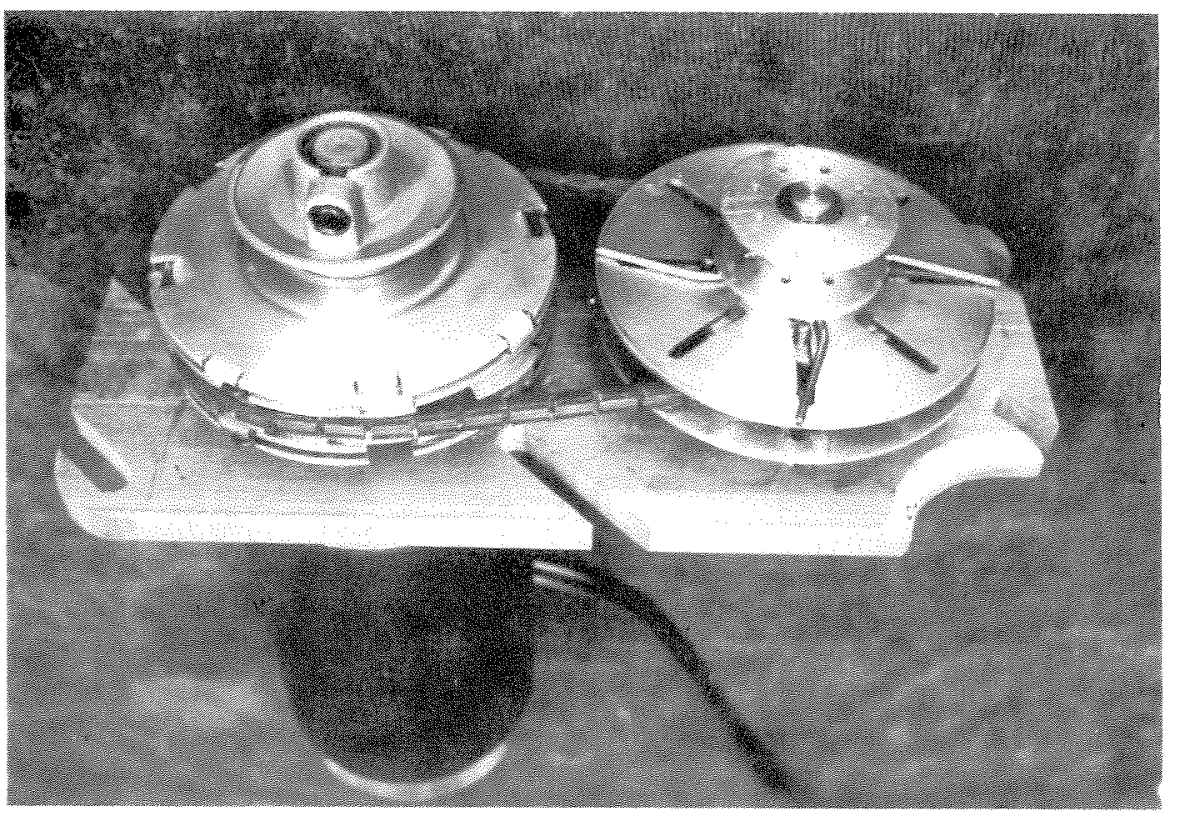

FIGURE 4

RESATRAN assembly with output pulleys on motor and driven pulley shafts.

installed. For the 20-inch wheel, speed in mph is given by rpm $\times 0.06$. An ammeter and voltometer were installed with the recognition that for a pulse-width modulated proportional control system, the ammeter reading would be only approximate, but believed to be sufficiently accurate for purposes of comparison. The vehicle is shown in Figure 5; Figure 6 shows the modified drive system.

As delivered, the vehicle has an overall speed reduction of $18: 1$. In its low-torque position, the RESATRAN has a speed-up of $0.56: 1$. It was not feasible to make the belt pulley on the RESATRAN output small enough to reproduce an 18:1 overall reduction, so a pulley diameter that produced an overall reduction of 14.5:1 was settled on. This meant that the vehicle would tend to go a bit faster at low-torque demand (a distinct advantage in some present wheelchairs). The maximum overall reduction at high-torque loads was then $14.5 \times 3.17$ or very close to $50: 1$, which increases the torque to the wheels by a factor of 2.8 as compared with the original drive.

The torque-measuring springs were designed and set so that speed ratio change would begin at about $1.2 \mathrm{ft}-1 \mathrm{~b}$ of motor torque. The spring rate was such that the drive pulley arms completely closed at $2.4 \mathrm{ft}-1 \mathrm{~b}$ motor torque. This was intended to permit level operation of the vehicle with little or no speed ratio change but with large speed ratio change on moderate to steep grades. The design represents a compromise since an optimum design would allow a smaller motor than that used by the manufacturer.

\section{Test Protocols}

Two kinds of tests were performed. First, some simple hill-climbing tests were planned to confirm the theoretical conclusions arrived at in THEORETICAL EXAMPLE. Second, simply driving the vehicle around a test course until the batteries became depleted was proposed to show whether the overall efficiency was improved.

The hill-climbing tests were performed on a relatively long 5 -degree ( 8.8 percent) hill. The author drove up this hill at various speeds and recorded the currents and speeds when they became steady.

The endurance tests were more challenging. The main difficulty was that the lack of personal spare time to drive the wheelchair a number of times from full charge to depletion. The problem was solved by obtaining two 5 ampere-hour motorcycle batteries for the tests. While these batteries were not "deep cycle," they could deliver substantial currents for a short time. Ten tests were performed, alternating between the direct drive and the RESATRAN for five of each. It was reasoned that changes in battery characteristics 
variations in charging, and differences in driving would average out over the tests. The batteries were charged each time to an open-circuit voltage of 25 volts. The wheelchair had an automatic lowvoltage cut-out that stopped the chair when the batteries reached a repeatable point of exhaustion. This point turned out to be quite marked as the vehicle would "die" very suddenly during a test. Each day of testing, the wheelchair was driven to the test course using the regular batteries, then the small batteries were connected and as far as possible, the course was negotiated at constant speeds until the vehicle stopped. The parameter noted was, of course, distance.

The test course, which was located in a park area, consisted of a macadam path that formed a loop, went up and down some grades, and entered and left a parking lot. The wheelchair was operated at $4.8 \mathrm{mph}(80 \mathrm{rpm})$ on the grades and at $5.4 \mathrm{mph}(90 \mathrm{rpm})$ on the level. The parking lot was looped once, stopping and starting at each of seven corners. The entire loop was just under 1 mile. Figure 8 shows a plan of the course.

\section{RESULTS}

\section{Hill Climbing Results}

The results of the hill-climbing tests are shown in Figure 7. Maximum speeds are those obtained at full voltage (24 volts nominal). Intermediate points are with proportional hand control in different positions. Current required at different speeds is shown for the normal drive and for the RESATRAN drive. At $3 \mathrm{mph}$ for each configuration, the required current is nearly 50 percent less for the RESATRAN drive. At full voltage and maximum speeds the current is 50 percent less with a speed drop of 24 percent. These values approximate those shown on Figure 1 at points $b$ and $b^{\prime}$, where the current is shown to drop 45 percent and the speed to drop 17 percent. (Actual operating parameters of the transmission do not exactly match those "assumed" for the calculation of Figure 1.)

\section{Distance Test Results}

Figure 8 shows in a plan of the test course the points where the vehicle stopped with batteries depleted. Odd numbers refer to the normal drive, and even numbers refer to the RESATRANequipped wheelchair. Figure 9 shows a bar graph indicating the means and standard deviations of the two sets of distances traveled. Downgrade distances were subtracted from the distances traveled since virtually no current was required at those times. (Since the normal drive chair stopped every time well short of the downgrades and the RESATRAN equipped chair negotiated one
FIGURE 5

The ElectroMobility CycleChair. ${ }^{\text {(TM }}$

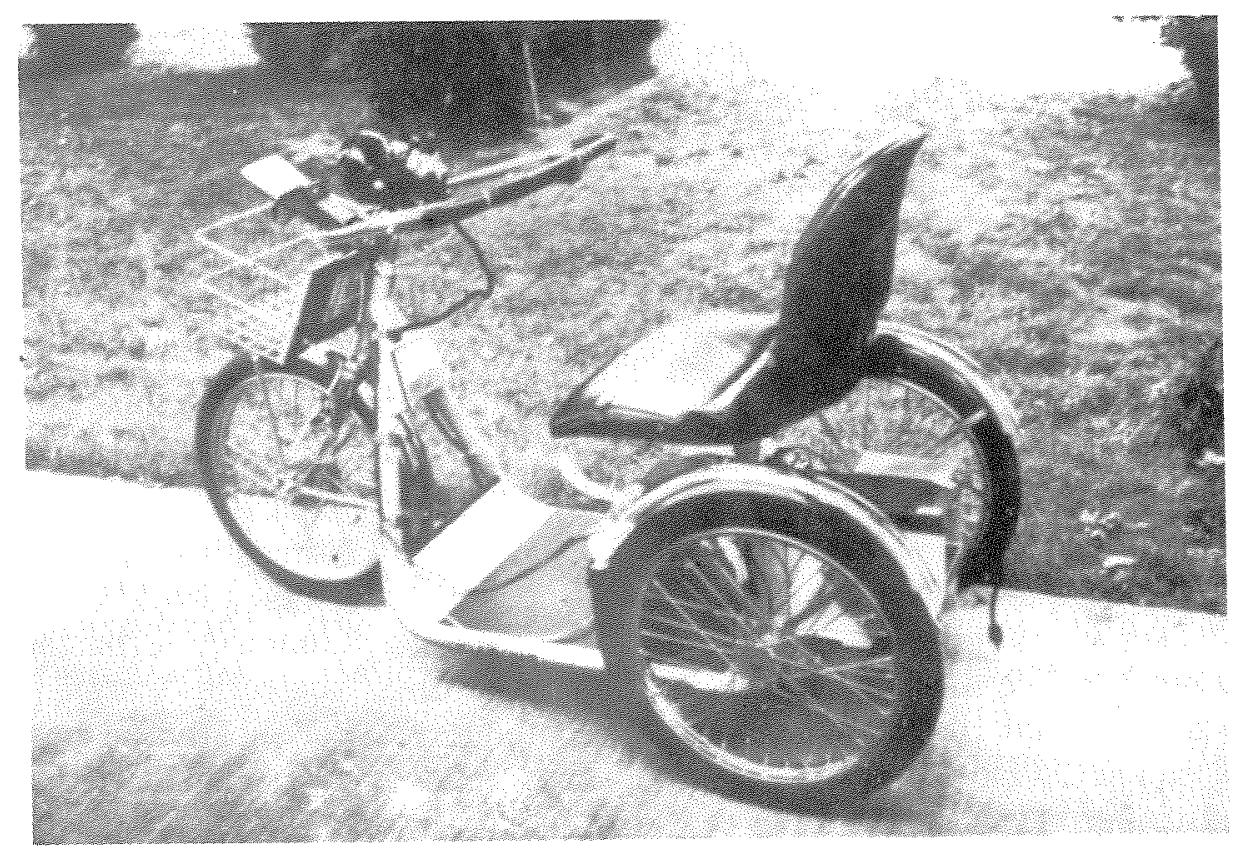



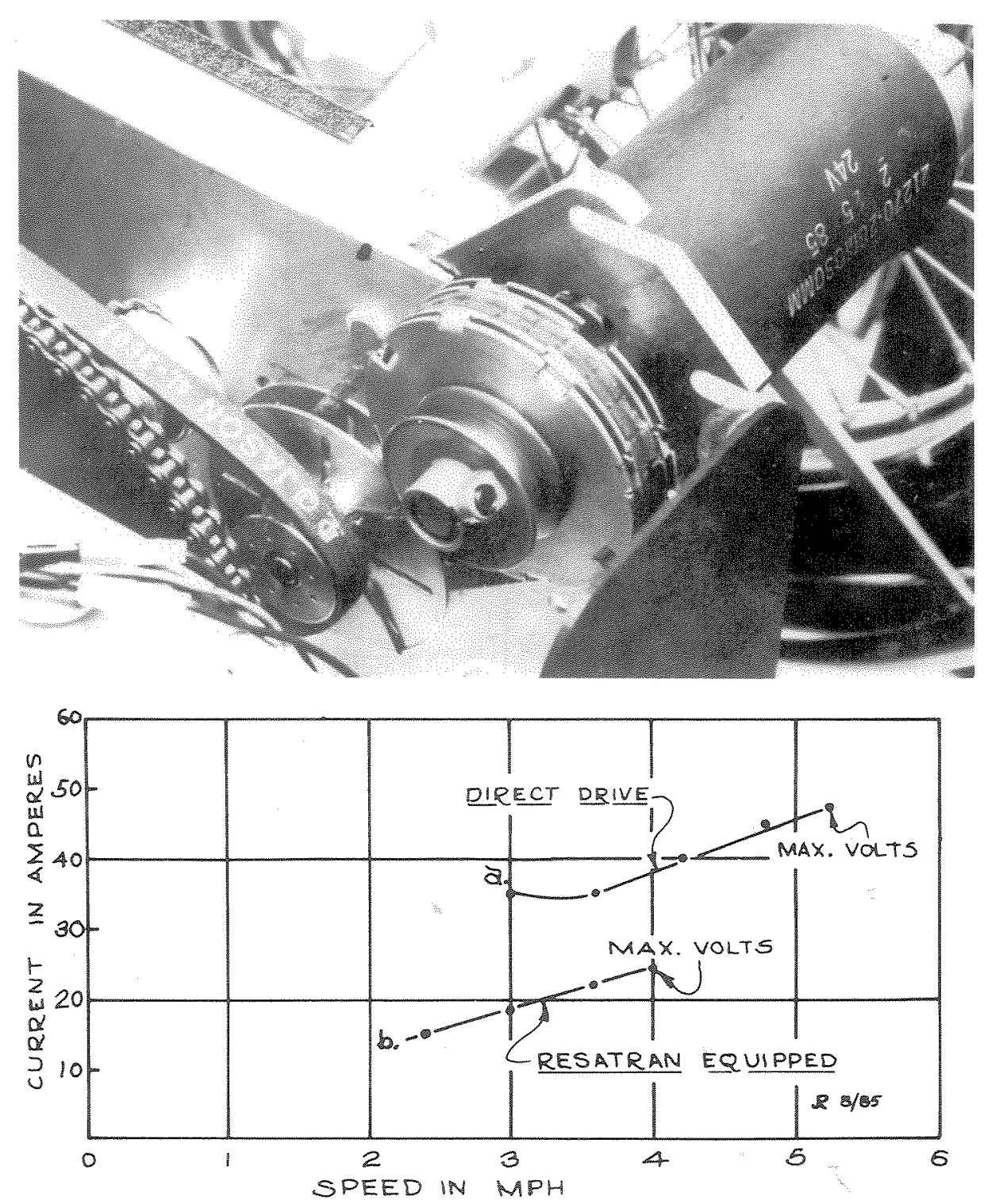

FIGURE 6

RESATRAN adaptation to wheelchair drive.

\section{FIGURE 7}

Amperes versus speed for wheelchair operated on an 8.8 percent grade. $A$ : normal; $B$ : with RESATRAN. slope every time and a second downgrade twice, it would have made it look unreasonably good to have included these distances). Figure 9 shows a 70 percent increase in average distance traveled for the RESATRAN equipped wheelchair as compared with the normal drive when operating under similar conditions. (Increase would have been 86 percent if downgrade distances had not been subtracted.)

\section{DISCUSSION}

The hill-climbing tests showed a marked reduction in required current when climbing hills with the RESATRAN. This was obtained without loss of speed performance on level surfaces. The current change and the speed loss were close to those predicted in THEORETICAL EXAMPLE. One would not expect exact agreement due to the fact that the characteristics of Figure 1 are ideal, the motor is not optimum for the chosen spring parameters and the operating conditions were different from those discussed in THEORETICAL EXAMPLE. But the magnitudes and the trends are close and give confidence that the theoretical results are achieveable.

Since the distance tests involved a good deal of hill climbing, the increase in operating range is to be expected. The amount of increase would 


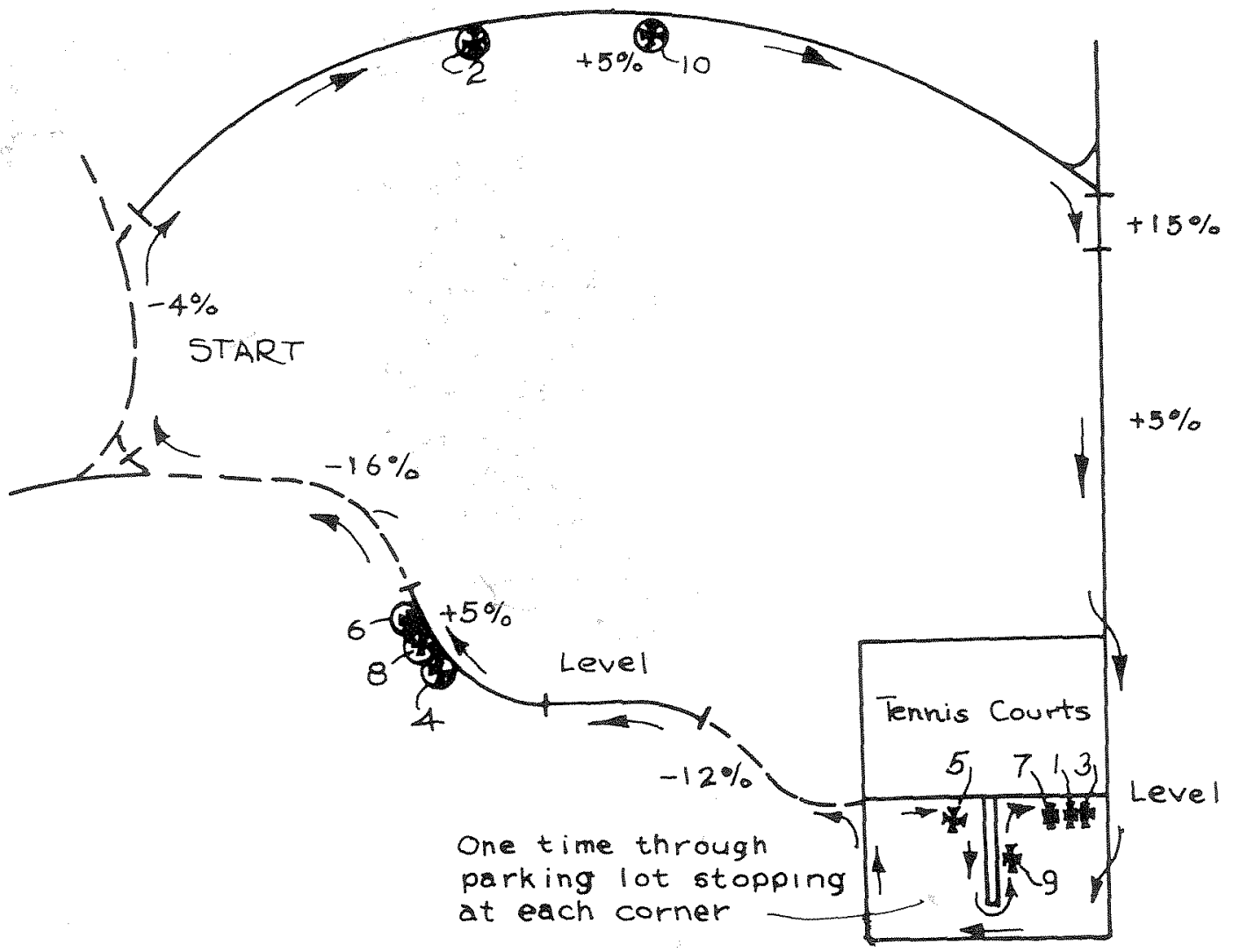

FIGURE 8

Endurance test track with final stopping points $\left(\theta_{0}\right)=$ direct; = RESATRAN) for each of 10 tests. Wheelchair test was performed on a macadam-paved walk path in a park area. Odd numbers $=$ normal wheelchair; even num-

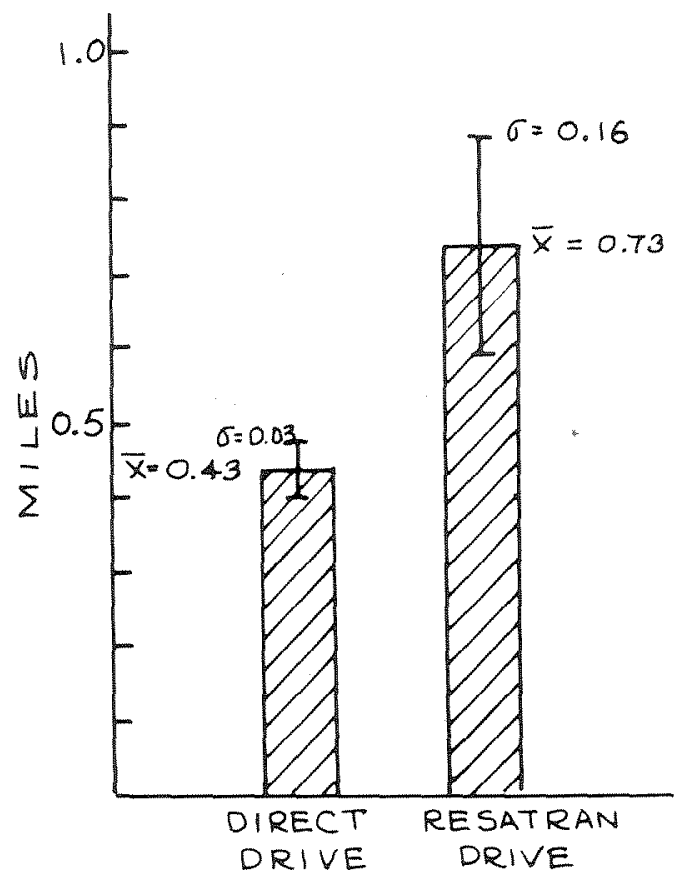

FIGURE 9

Average distances traveled with and without RESATRAN transmission. bers = RESATRAN-equipped wheelchair. Dashed lines $=$ downgrades. Only trials 2 and 10 completed the course. All other trials depleted the batteries before the course was completed.

depend on the ratio of hill climbing to level operation. Very little difference would be expected when operating at constant speed on a level smooth surface. But it is believed that starts and stops and hill climbing are representative of many wheelchair applications and that the results, while somewhat arbitrary, are indeed significant.

Many questions remain to be answered. The RESATRAN does function as intended and produces the desired results. It remains to be seen if it is reliable and durable. The study used a singlemotor driven wheelchair. How the RESATRAN transmission would affect the steering and control of a dual-motor wheelchair remains to be determined. The cost of a mass-produced device is unknown and of critical importance, for it must be cost-effective if the gains to be achieved are to be worth more than the cost to obtain them. However, there are no critical tolerances in any of the parts, and most of them can be made from plastic or inexpensive stampings. 


\section{CONCLUSION}

The theoretical gains to be obtained from the application of a torque-responsive variable speed transmission to electric wheelchair propulsion are presented. The design details of a new variable-speed transmission are presented, and a prototype has been built and tested on a commercially available wheelchair. The results support the theoretical expectations and are encouraging. 